CZASOPISMO INŻYNIERII LĄDOWEJ, ŚRODOWISKA I ARCHITEKTURY JOURNAL OF CIVIL ENGINEERING, ENVIRONMENT AND ARCHITECTURE JCEEA, t. XXXIII, z. 63 (1/I/16), styczeń-marzec 2016, s. 397-404

\author{
Mykhaylo DELYAVSKYY ${ }^{1}$ \\ Krystian ROSIŃSKI ${ }^{2}$
}

\title{
ANALIZA STATYCZNA ZŁOŻONYCH KONSTRUKCJI PŁYTOWYCH W UJĘCIU MAKROELEMENTOWYM
}

\begin{abstract}
Opracowano nowe podejście do rozwiązania złożonych konstrukcji płytowych, nazwane metodą makroelementów. Rozważa się cienką płytę o grubości $h$ i ciąg prostokątów, z których każdy całkowicie zawiera w sobie kontur płyty rzeczywistej. Kres dolny tego ciągu jest konturem $L_{0}$ makroelementu płytowego. Makroelementem płytowym jest połączenie płyty rzeczywistej $P$ i jej dopełnienia $\partial P$ do obszaru prostokątnego ograniczonego konturem $L_{0}$. Każdej płycie odpowiada jeden makroelement. W ramach teorii płyt cienkich izotropowych, wszystkie makroelementy opisuje jeden model matematyczny. W referacie model taki został opracowany jako zbiór wyrażeń na przemieszczenia, momenty i siły tnące $\mathrm{z}$ niewiadomymi parametrami. Każde wyrażenie składa się z sumy wielomianu, funkcji kształtu pomnożonych przez te parametry i funkcji obciążenia. Modelowanie konstrukcji polega na zapisie warunków brzegowych i warunków ciągłości w węzłach rozmieszczonych na krawędziach zewnętrznych i wewnętrznych układu. Tymi węzłami są punkty zerowe funkcji trygonometrycznych, wchodzących do modelu. Dla układów posiadających osie symetrii geometrycznej i mechanicznej dodatkowo zapisuje się warunki symetryczności w środkach krawędzi makroelementu. Za pomocą opracowanej metody otrzymano szereg rozwiązań konstrukcji płytowych. W referacie podano rozwiązanie płyty wspornikowej obciążonej symetrycznie na powierzchni górnej. Rozwiązanie otrzymano z dużą dokładnością. Wykazano efektywność opracowanej metody.
\end{abstract}

Słowa kluczowe: metoda, makroelementy, model matematyczny, płyta, punkty zerowe, funkcje kształtu

\section{Wstęp}

W chwili obecnej ogólnie przyjętą i najbardziej rozpowszechnioną metodą rozwiązywania konstrukcji inżynierskich jest metoda elementów skończonych

\footnotetext{
${ }^{1}$ Autor do korespondencji/corresponding author : Mykhaylo Delyavskyy, Wydział Budownictwa, Architektury i Inżynierii Środowiska, Uniwersytet Technologiczno-Przyrodniczy w Bydgoszczy, ul. Prof. S. Kaliskiego 7, 85-796 Bydgoszcz, tel. +48 667603 211, e-mail: delyavmv@utp.edu.pl

${ }^{2}$ Krystian Rosiński, Wydział Budownictwa, Architektury i Inżynierii Środowiska, Uniwersytet Technologiczno-Przyrodniczy w Bydgoszczy, ul. Prof. S. Kaliskiego 7, 85-796 Bydgoszcz, tel. +48 782858 907, e-mail: krystian.rosinski@utp.edu.pl
} 
(MES), która należy do grupy metod numerycznych. W referacie proponuje się inne podejście $[1,2,3]$ do rozwiązania konstrukcji nazwane metodą makroelementów (MME). Zgodnie z MES konstrukcję dzielimy na wiele drobnych części zwanych elementami skończonymi. Natomiast w opracowanym podejściu konstrukcję dzieli się na dość duże części zwane makroelementami. Są one w istocie częściami konstrukcji rzeczywistej.

\section{Budowa makroelementu płytowego}

Rozważmy cienką płytę izotropową o dowolnym kształcie, której kontur jest wpisany w obszar prostokątny $P_{n}$, przy czym kontur płyty może mieć nieskończenie wiele punktów wspólnych z prostokątem (płyta prostokątna o tych samych wymiarach) lub nie mieć żadnych punktów wspólnych. Zrozumiałym jest, że istnieje nieskończenie wiele takich obszarów prostokątnych. Każdy z nich będzie zawierać w sobie kontur płyty rzeczywistej. $Z$ tych obszarów zawsze można zbudować ciągły ciąg $\left\{P_{n}\right\}$. Dolny kres $\inf \left\{P_{n}\right\}$ tego ciągu nazwijmy makroelementem płytowym [4].

Do dalszych rozważań przyjmijmy cienką płytę izotropową prostokątną o grubości $h$ i wymiarach w rzucie $2 a_{j},(j=1,2)$ (makroelement płytowy) i odnieśmy ją do kartezjańskiego układu współrzędnych $O x_{1} x_{2} x_{3}$ z początkiem w geometrycznym środku płyty. Oś $O x_{3}$ kierujemy w dół, a osie $O x_{1}$ i $O x_{2}$ rozmieszczamy w płaszczyźnie środkowej płyty tak, aby układ współrzędnych był prawoskrętny. Górna powierzchnia płyty jest obciążona obciążeniem dowolnym o intensywności $q\left(x_{1}, x_{2}\right)$, a dolna powierzchnia jest nieobciążona.

Równowaga sprężysta takiej płyty opisywana jest równaniem różniczkowym cząstkowym ze stałymi współczynnikami

$$
\nabla^{2} \nabla^{2} w=\frac{q}{D}
$$

Tutaj $w$ jest funkcją ugięcia płyty, a $D$ sztywnością płyty na zginanie.

Rozwiązanie równania podstawowego (1) wybieramy w postaci sumy dwóch rozwiązań:

$$
w=w_{0}+w_{*}
$$

całki ogólnej $w_{0}$ równania jednorodnego

$$
\nabla^{2} \nabla^{2} w=0
$$

i całki szczególnej $w_{*}$ niejednorodnego równania (1).

W celu określenia całki szczególnej, obciążenie zewnętrzne rozwijamy w szesnaście podwójnych szeregów Fouriera [1,5].

$$
q\left(x_{1}, x_{2}\right)=Q_{m n p q} T_{m p}^{[1]}\left(x_{1}\right) \cdot T_{n q}^{[2]}\left(x_{2}\right)
$$


gdzie $Q_{m n p q}$ to współczynniki rozwinięcia funkcji $q\left(x_{1}, x_{2}\right)$ w szeregi trygonometryczne.

$$
\begin{aligned}
& T_{m 1}^{[j]}\left(x_{j}\right)=\cos \left(\gamma_{m}^{[j]} x_{j}\right) ; T_{m 2}^{[j]}\left(x_{j}\right)=\cos \left(\delta_{m}^{[j]} x_{j}\right) ; \\
& T_{m 3}^{[j]}\left(x_{j}\right)=\sin \left(\delta_{m}^{[j]} x_{j}\right) ; T_{m 4}^{[j]}\left(x_{j}\right)=\sin \left(\gamma_{m}^{[j]} x_{j}\right) ; \\
& \delta_{m}^{[1]}=\frac{(2 m-1) \pi}{2 a_{1}} ; \delta_{n}^{[2]}=\frac{(2 n-1) \pi}{2 a_{2}} ; \gamma_{m}^{[1]}=\frac{m \pi}{a_{1}} ; \gamma_{n}^{[2]}=\frac{n \pi}{a_{2}} ;
\end{aligned}
$$

W podobnej postaci wybieramy całkę szczególną równania (1):

$$
w_{*}\left(x_{1}, x_{2}\right)=C_{m n p q} W_{m n p q}^{*}\left(x_{1}, x_{2}\right) .
$$

gdzie $C_{m n p q}$ - są to nieznane współczynniki, które określamy z rozwiązania równania (1). Funkcje

$$
W_{m n p q}^{*}\left(x_{1}, x_{2}\right)=T_{m p}^{[1]}\left(x_{1}\right) \cdot T_{n q}^{[2]}\left(x_{2}\right)
$$

nazwano funkcjami obciążeniowymi ugięcia płyty. Tutaj i w dalszych rozważaniach wykorzystuje się zasadę sumacyjną Einsteina: w każdym wyrażeniu wykonuje się sumowanie względem wskaźnika, który powtarza się dwa razy: $p, q=1 \div 4 ; m, n=1 \div \infty$.

Całkę ogólną $w_{0}\left(x_{1}, x_{2}\right)$ jednorodnego równania (3) wybieramy w postaci:

$$
w_{0}=A_{i} \Phi_{i}\left(x_{1}, x_{2}\right)+f_{k p}^{[j]}\left(x_{j}\right) \cdot T_{k p}^{[3-j]}\left(x_{3-j}\right) .
$$

Tutaj $k=1 \div K$, gdzie $K$ jest liczbą aproksymacji. Natomiast $A_{i}(i=0 \div 12)$ są to niewiadome współczynniki, które określane są $\mathrm{w}$ procesie rozwiązania zagadnienia.

$$
\begin{array}{ccc}
\Phi_{0}\left(x_{1}, x_{2}\right)=1 ; & \Phi_{1}\left(x_{1}, x_{2}\right)=\frac{x_{1}}{a_{1}} ; & \Phi_{2}\left(x_{1}, x_{2}\right)=\frac{x_{2}}{a_{2}} ; \\
\Phi_{3}\left(x_{1}, x_{2}\right)=\frac{x_{1} x_{2}}{a_{1} a_{2}} ; & \Phi_{4}\left(x_{1}, x_{2}\right)=\frac{x_{1}^{2}}{a_{1}^{2}} ; & \Phi_{5}\left(x_{1}, x_{2}\right)=\frac{x_{2}^{2}}{a_{2}^{2}} ; \\
\Phi_{6}\left(x_{1}, x_{2}\right)=\frac{x_{1}^{2} x_{2}}{a_{1}^{2} a_{2}} ; & \Phi_{7}\left(x_{1}, x_{2}\right)=\frac{x_{1} x_{2}^{2}}{a_{1} a_{2}^{2}} ; & \Phi_{8}\left(x_{1}, x_{2}\right)=\frac{x_{1}^{3}}{a_{1}^{3}} \\
\Phi_{9}\left(x_{1}, x_{2}\right)=\frac{x_{2}^{3}}{a_{2}^{3}} ; & \Phi_{10}\left(x_{1}, x_{2}\right)=\frac{x_{1} x_{2}^{3}}{a_{1} a_{2}^{3}} ; & \Phi_{11}\left(x_{1}, x_{2}\right)=\frac{x_{1}^{3} x_{2}}{a_{1}^{3} a_{2}} ; \\
\Phi_{12}\left(x_{1}, x_{2}\right)=\frac{x_{1}^{4}-x_{2}^{4}}{a_{1}^{4}} ; &
\end{array}
$$


Funkcje $f_{k p}^{[j]}\left(x_{j}\right)$ mają postać [6,7]:

$$
f_{k p}^{[j]}\left(x_{j}\right)=R_{k p v}^{[j]} B_{k p v}^{[j]}\left(x_{j}\right), \quad v=1 \div 4 .
$$

W powyższym wyrażeniu

$$
\begin{aligned}
& B_{k p 1}^{[j]}\left(x_{j}\right)=\frac{\cosh \left(\kappa_{k p}^{[j]} x_{j}\right)}{\exp \left(\kappa_{k p}^{[j]} a_{j}\right)}, \quad B_{k p 2}^{[j]}\left(x_{j}\right)=\frac{x_{j} \sinh \left(\kappa_{k p}^{[j]} x_{j}\right)}{a_{j} \exp \left(\kappa_{k p}^{[j]} a_{j}\right)}, \\
& B_{k p 3}^{[j]}\left(x_{j}\right)=\frac{\sinh \left(\kappa_{k p}^{[j]} x_{j}\right)}{\exp \left(\kappa_{k p}^{[j]} a_{j}\right)}, \quad B_{k p 4}^{[j]}\left(x_{j}\right)=\frac{x_{j} \cosh \left(\kappa_{k p}^{[j]} x_{j}\right)}{a_{j} \exp \left(\kappa_{k p}^{[j]} a_{j}\right)},
\end{aligned}
$$

gdzie

$$
\kappa_{k p}^{[j]}= \begin{cases}\gamma_{k}^{[j]}, & p=1,3, \\ \delta_{k}^{[j]}, & p=2,4 .\end{cases}
$$

Funkcje $B_{k p v}^{[j]}\left(x_{j}\right)$ nazwano funkcjami bazowymi modelu. Oczywistym jest, że $B_{k 1 v}^{[j]}\left(x_{j}\right)=B_{k 4 v}^{[j]}\left(x_{j}\right)$ oraz $B_{k 2 v}^{[j]}\left(x_{j}\right)=B_{k 3 v}^{[j]}\left(x_{j}\right)$. Uwzględniając zależności (2), (8), (10) zapisujemy wyrażenie ugięcia płyty w postaci:

$$
w\left(x_{1}, x_{2}\right)=A_{r} \Phi_{r}\left(x_{1}, x_{2}\right)+R_{k p v}^{[j]} W_{k p v}^{[j]}\left(x_{1}, x_{2}\right)+w_{*}\left(x_{1}, x_{2}\right)
$$

gdzie

$$
W_{k p v}^{[j]}\left(x_{1}, x_{2}\right)=B_{k p v}^{[j]}\left(x_{j}\right) T_{k p}^{[3-j]}\left(x_{3-j}\right) .
$$

są funkcjami kształtu ugięcia płyty.

W wyrażeniu (13) dokonuje się sumowania względem wskaźników $v, p, k, r$. W przypadku (14) nie dokonujemy sumowania, gdyż wskaźniki występują po obu stronach wyrażenia.

Mając wyrażenie na ugięcie płyty określamy przemieszczenia styczne, momenty i siły poprzeczne przez odpowiednie funkcje kształtu i funkcje obciążeniowe.

Modelowanie pracy konstrukcji płytowej polega na zapisie warunków brzegowych i warunków ciągłości w oddzielnych punktach węzłowych na krawędziach, a także warunków symetryczności (dla zagadnień symetrycznych) zapisanych w punktach środkowych krawędzi.

Badania numeryczne wykazały, że najlepszą dokładność rozwiązania osiąga się gdy punkty węzłowe, w których spełniamy warunki brzegowe wybiera się jako punkty zerowania się funkcji trygonometrycznych, przy zadanej wartości $k=K$. Mamy zatem: 


$$
\cos \gamma_{k}^{[j]} x_{j}=\cos \frac{K \pi}{a_{j}} x_{j}=0, \text { skąd } \frac{K \pi}{a_{j}} \bar{x}_{j}=\frac{(2 n-1) \pi}{2}, \bar{x}_{j}=\frac{2 n-1}{2 K} a_{j} .
$$

Tutaj $n=1 \div K$, natomiast $\bar{x}_{j}$ są pierwiastkami równania trygonometrycznego (punktami zerowymi dla funkcji $\cos \gamma_{k}^{[j]} x_{j}$ ). Podobnie

$$
\begin{aligned}
& \cos \delta_{k}^{[j]} x_{j}=\cos \frac{(2 K-1) \pi}{2 a_{j}} x_{j}=0, \text { skąd } \\
& \frac{(2 K-1) \pi}{2 a_{j}} \bar{x}_{j}=\frac{(2 n-1) \pi}{2}, \bar{x}_{j}=\frac{2 n-1}{2 K-1} a_{j}, \\
& \sin \gamma_{k}^{[j]} x_{j}=\sin \frac{K \pi}{a_{j}} x_{j}=0, \text { skąd } \frac{K \pi}{a_{j}} \bar{x}_{j}=n \pi, \bar{x}_{j}=\frac{n}{K} a_{j}, \\
& \sin \delta_{k}^{[j]} x_{j}=\sin \frac{(2 K-1) \pi}{2 a_{j}} x_{j}=0, \text { skąd } \\
& \frac{(2 K-1) \pi}{2 a_{j}} \bar{x}_{j}=(n-1) \pi, \bar{x}_{j}=\frac{2(n-1)}{2 K-1} a_{j} .
\end{aligned}
$$

W taki sposób dla zadanej aproksymacji $K$ każda funkcja trygonometryczna ma $K$ punktów zerowych, które za wyjątkiem funkcji $\sin \delta_{k}^{[j]} x_{j}$ dla $n=1$ nie pokrywają się z punktami środkowymi krawędzi płyty. W punktach środkowych krawędzi płyty warunki brzegowe spełniamy przy pomocy współczynników wielomianu wchodzącego do wyrażenia (8).

Ponieważ funkcja $\sin \delta_{k}^{[j]} x_{j}$ dla $n=1$ ma punkt zerowy w środku krawędzi $\left(x_{j}=0\right)$ to dla niej proponuje się taki wybór punktów zerowych:

$$
\bar{x}_{J}=\left\{\begin{array}{cc}
\frac{1}{2 K} a_{j}, & n=1 \\
\frac{2(n-1)}{2 K-1} a_{j}, & n>1
\end{array}\right.
$$

Punkty zerowe parzystych funkcji trygonometrycznych rozmieszczamy na dodatnich częściach krawędzi płyt i przyjmujemy ich współrzędne ze znakiem „,+”, natomiast punkty zerowe nieparzystych funkcji rozmieszczamy na ujemnych częściach krawędzi płyty i przyjmujemy je ze znakiem ,,-”. W każdym punkcie zerowym zapisujemy po dwa warunki brzegowe, więc dla pierwszej aproksymacji $(K=1)$ warunki brzegowe zapisujemy od razu w dwóch punktach na każdej krawędzi płyty. W punktach środkowych krawędzi na konturze płyty zawsze zapisujemy 8 warunków brzegowych niezależnie od liczby aproksymacji. Ponieważ dla ich spełnienia mamy 13 współczynników, to w procesie rozwiązania muszą być nałożone dodatkowe więzy na te współczynniki. Dla zagadnień symetrycznych w punktach środkowych płyty dodatkowo zapisujemy warunki symetryczności. 


\section{Przykład obliczeniowy - płyta wspornikowa}

$\mathrm{W}$ rozważanym poniżej przykładzie rozwiązanie otrzymano $\mathrm{w}$ trzecim przybliżeniu $(\mathrm{K}=3)$. W tym przypadku na konturze płyty wybrano 4 punkty środkowe i 48 punktów zerowych.

Rys. 1. Schemat płyty

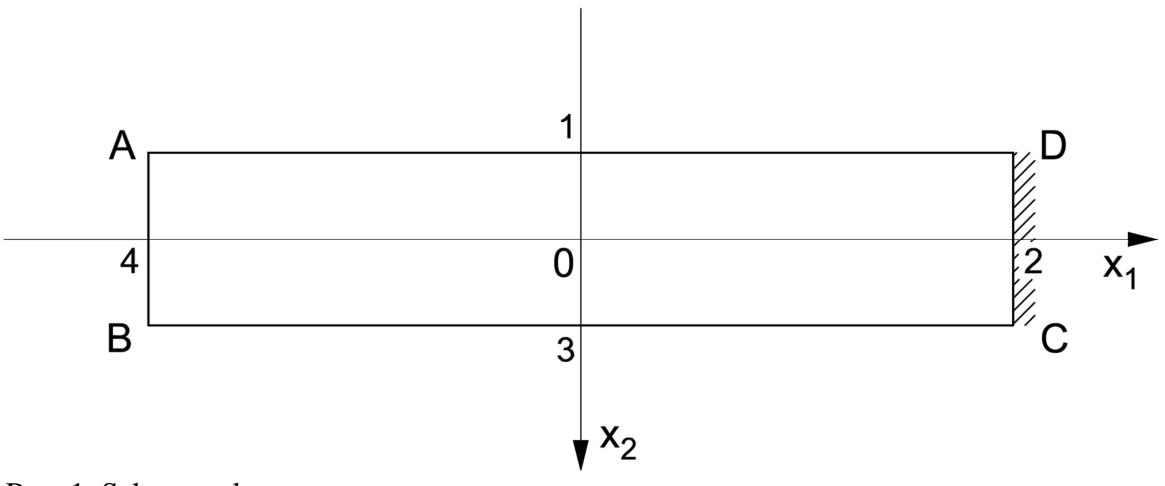

Fig. 1. Scheme of the plate

Rozpatrujemy przypadek płyty o krawędzi CD zamocowanej i pozostałych krawędziach swobodnych, obciążonej obustronnie symetrycznie. Otrzymujemy zagadnienie symetryczne względem osi $x_{1}$ i niesymetryczne względem osi $x_{2}$.

$\mathrm{Na}$ krawędzi zamocowanej zapisujemy warunki

$$
w\left(a_{1}, x_{2}\right)=0, \frac{\partial w\left(a_{1}, x_{2}\right)}{\partial x_{1}}=0,
$$

a na krawędzi przeciwległej $\mathrm{AB}$ warunki

$$
M_{11}\left(-a_{1}, x_{2}\right)=0, \quad V_{1}\left(-a_{1}, x_{2}\right)=0 .
$$

Na krawędziach swobodnych podłużnych zapisujemy warunki

$$
M_{22}\left(x_{1}, \pm a_{2}\right)=0, \quad V_{2}\left(x_{1}, \pm a_{2}\right)=0 .
$$

Ponieważ warunki brzegowe są ciągłe, to spełniamy je w punktach zerowych na krawędziach płyty, jak również w punktach środkowych krawędzi. W punktach tych zapisujemy po dwa warunki brzegowe. Ze względu na symetrię konstrukcji względem osi $O x_{1}$ dodatkowo zapisujemy warunki symetryczności [8] w punktach 2 i 4 odpowiednio:

$$
\frac{\partial w\left(a_{1}, 0\right)}{\partial x_{2}}=0, \quad \frac{\partial^{2} w\left(-a_{1}, 0\right)}{\partial x_{1} \partial x_{2}}=0 .
$$

Mamy trzy zbędne współczynniki. Przyjmujemy zatem: 


$$
A_{3}=A_{10}=A_{11}=0 .
$$

W ten sposób otrzymujemy układ 104 równań brzegowych i 2 równań symetryczności.

Do obliczeń przyjęto następujące wymiary płyty $2 a_{1}=30 \mathrm{~m}, 2 a_{2}=6 \mathrm{~m}$, $h=0,3 \mathrm{~m}$, wartość obciążenia powierzchni górnej $q=10 \mathrm{kN} / \mathrm{m}^{2}$ oraz następujące właściwości materiałowe: moduł Younga $E=2,1 \cdot 10^{4} \mathrm{MN} / \mathrm{m}^{2}$ oraz współczynnik Poissona $v=0,3$.

Na rysunkach podano wykresy zmiany ugięcia $w$ i momentu zginającego $M_{11}$ w przekroju środkowym podłużnym płyty. Warunki brzegowe dla ugięcia i kątów obrotu normalnej do powierzchni środkowej płyty na krawędzi zamocowanej spełnione są z dokładnością odpowiednio $10^{-16}$ i $10^{-12}$.

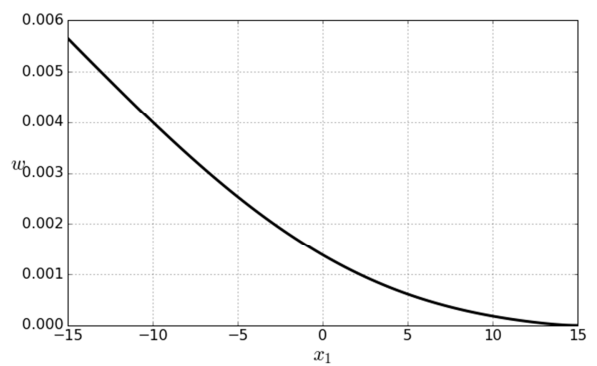

Rys. 2. Wykres ugięcia $w$ płyty

Fig. 2. Plot of the plate deflection $w$

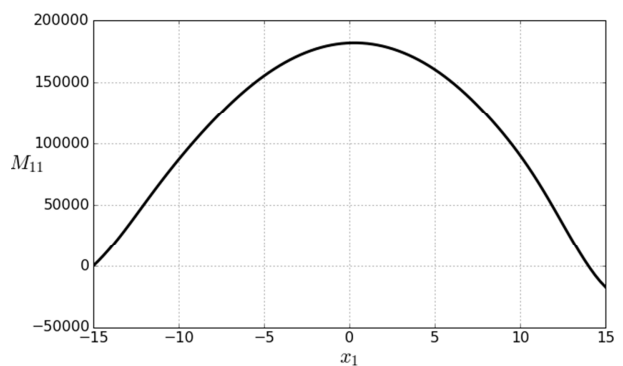

Rys. 3. Wykres momentu zginającego $M_{11}$

Fig. 3. Plot of the bending moment $M_{11}$

Obliczenia wykonano w trzeciej aproksymacji $(K=3)$. Na krawędziach poprzecznych i podłużnych warunki brzegowe spełniono w punktach środkowych i narożnikowych oraz punktach pośrednich określonych wzorami (15)-(18).

\section{Podsumowanie}

Opracowano nowe podejście do rozwiązania konstrukcji płytowych nazwane metodą makroelementów, które opiera się na dokładnym rozwiązaniu równań równowagi. Przemieszczenia, momenty i siły tnące wyrażają się przez własne funkcje kształtu i funkcje obciążeniowe. Warunki brzegowe zostały spełnione w punktach zerowych funkcji trygonometrycznych. Wykazano dużą dokładność rozwiązania.

\section{Literatura}

[1] Delyavskyy M., Rosiński K.: Rozwiązanie konstrukcji inżynierskich w ujęciu makroelementowym. Wybrane zagadnienia konstrukcji i materiałów budowlanych oraz geotechniki. Wyd. UTP w Bydgoszczy, 2015, s. 37-44.

[2] Delyavskyy M., Rosiński K.: Metoda rozwiązywania układów płytowo-kratowych, Bridges, Tradition and Future, 2013, s.39-49. 
[3] Delyavskyy M., Gołaś J., Olejniczak M.: Analiza statyczna cienkich płyt ortotropowych w ujęciu macierzowym, Zagadnienia Mechaniki Stosowanej, 2013, s. 9-22

[4] Delyavskyy M., Niespodziana A., Buchaniec D.: Rozwiązywanie cienkich płyt żelbetowych metodą elementów konstrukcyjnych, SCIENTARIUM POLONORUM ACTA, Architektura, 2011, s. 3-14.

[5] Делявський М., Здолбіцька Н., Онишко Л., Здолбіцький А. Визначення напружено-деформованого станув тонких плитах ортотропних плитах на пружній основі Вінклера, Фізико-хімічна Механіка Матеріалів, 2014, № 6, С. 15-22.

[6] Делявський М.В., Здолбіцька Н.В., Здолбіцький А.П.: Метод конструкційних елементів у розрахунку плит складної конфігурації на пружній основі, Луцьк: ЛНТУ, 2012.

[7] Delyavskyy M., Rosiński K.: Modelowanie płyty grubej złożonej z trzech różnych warstw drewnianych, Drewno i materiały drewnopochodne w konstrukcjach budowlanych, Szczecin, 2011, s. 19-33.

[8] Delyavskyy M., Niespodziana A., Olejniczak M., Grabowski A., Rosiński K.: Analiza statyczna płyty izotropowej o średniej grubości. Wybrane zagadnienia konstrukcji i materiałów budowlanych oraz geotechniki, Wydawnictwo Uczelniane UTP w Bydgoszczy, 2015, s. 25-36.

\section{STATIC ANALYSIS OF COMPOUND PLATE STRUCTURES IN CONCEPTION OF MACROELEMENT}

\section{S u m m a r y}

New approach to solve complex plate structures, called the macroelement method has been developed. There is considered thin plate having a thickness $h$ and a series of rectangles, each of which completely contains the real contour of the plate. The lower bound of this sequence is a contour $L_{0}$ of the plate macroelement. Plate macroelement is connection of the real plate $P$ and its addition $\partial P$ to the rectangular area bounded by contour $L_{0}$. Each plate has one macroelement. Within the theory of thin isotropic plates, all macroelements are described in the frame of one mathematical model. In this paper, this model has been developed as a set of expressions for displacements, moments and shear forces with unknown parameters. Each expression is the sum of the polynomial, shape functions multiplied by the unknown parameters and loading function. Modelling the structure is to write a boundary conditions and conditions of continuity at the nodes located on the outer and inner edges. These nodes are zero points of trigonometric functions, included in the model. For systems having geometrical and mechanical symmetry we additionally write symmetrical conditions in the center of macroelement edges. The series of solutions for plates structures has been obtained using this method. The paper presents solution for one hand side clamped plate loaded symmetrically on the upper surface. The solution obtained with high accuracy. It demonstrates the effectiveness of this method.

Keywords: method, macroelements, mathematical model, plate, zero of a function, shape functions

Przestano do redakcji: 07.06.2016 $r$.

Przyjęto do druku: 30.06 .2016 r.

DOI: $10.7862 / \mathrm{rb} .2016 .47$ 